\title{
Consultation, Diagnosis and Treatment Delays for Breast Cancer among Patients Followed up at the Yaoundé General Hospital, Cameroon
}

\author{
Jean Dupont Kemfang Ngowa ${ }^{1,2^{*}}$, Angèle Kabeyene ${ }^{3}$, Richard Ngarvounsia ${ }^{1}$, Etienne Atenguena ${ }^{4}$, \\ Yvan Sinclair Ngaha Tchawe1, Anny Ngassam ${ }^{1}$, Christiane Nsahlai ${ }^{1}$, Junie Metogo ${ }^{1}$, \\ Jovanny Fouogue Tsuala ${ }^{5}$, Pierre Marie Tebeu ${ }^{1}$

\footnotetext{
${ }^{1}$ Department of Obstetrics/Gynecology, Faculty of Medicine and Biomedical Sciences, University of Yaoundé I, Yaoundé, Cameroon ${ }^{2}$ Yaoundé General Hospital, Obstetrics/Gynecology Unit, Yaoundé, Cameroon

${ }^{3}$ Department of Pathology, Faculty of Medicine and Biomedical Sciences, University of Yaoundé I, Yaoundé, Cameroon ${ }^{4}$ Yaoundé General Hospital, Medical Oncology Unit, Yaoundé, Cameroon

${ }^{5}$ Department of Obstetrics/Gynecology, Faculty of Medicine and Pharmaceutical Sciences, University of Dschang, Dschang, Cameroon Email: ‘jdkemfang@yahoo.fr
}

How to cite this paper: Kemfang Ngowa, J.D., Kabeyene, A., Ngarvounsia, R., Atenguena, E., Ngaha Tchawe, Y.S., Ngassam, A., Nsahlai, C., Metogo, J., Fouogue Tsuala, J. and Tebeu, P.M. (2020) Consultation, Diagnosis and Treatment Delays for Breast Cancer among Patients Followed up at the Yaoundé General Hospital, Cameroon. Open Journal of Obstetrics and Gynecology, 10, 1580-1589.

https://doi.org/10.4236/ojog.2020.10110142

Received: October 2, 2020

Accepted: November 13, 2020

Published: November 16, 2020

Copyright $\odot 2020$ by author(s) and Scientific Research Publishing Inc. This work is licensed under the Creative Commons Attribution International License (CC BY 4.0).

http://creativecommons.org/licenses/by/4.0/

(c) (i) Open Access

\begin{abstract}
Introduction: Breast cancer is often diagnosed at an advanced stage in $\mathrm{Ca}$ meroon. The objective was to analyse consultation, diagnosis and treatment delays for breast cancer among patients followed up at the Yaoundé General Hospital (YGH) in Cameroon. Materials and Methods: This was a cross-sectional study carried out from the files of patients followed up for breast cancer at the YGH from January 1, 2014 to April 30, 2018. A total of 183 patients were included. We measured time elapsed between the awareness of first signs of disease and the initial consultation (consultation delays), time lapse between the initial consultation and pathological diagnosis of breast cancer (diagnosis delays), interval between pathological diagnosis and treatment onset (treatment delays), time elapsed between the initial consultation and management (health system delays) and time elapsed from awareness of first signs of disease to treatment onset (overall delays). Results: The delays (median, IIQ) were: (5.1 months; IIQ: 1.7 - 12.4), (25 days; IIQ: 10 67), (27 days; IIQ: 13 - 63), (2.2 months; IIQ: 1.2 - 5.8) and (9.9 months; IIQ: 4.4 - 17.6) respectively for consultation, diagnosis, treatment, health system and overall delays. The risks associated with a delay in initial consultation of greater than 3 months were (OR; 95\% CI): unschooled patients (2.01; 1.66 $2.40)$; monthly income below the minimum wage (2.70; 1.81 - 5.96); unemployment $(2.14 ; 1.02-3.24)$ and absence of a family history of cancer $(2.44$; $1.66-6.10)$. The main reasons for a late first consultation were: ignorance
\end{abstract}


(60.2\%), financial challenges $(17.6 \%)$ and a preference for alternative treatment $(11.1 \%)$. Conclusion: The consultation, diagnosis and treatment delays for breast cancer are very often long in our setting than those reported in developed countries. Both patients' and institutional factors are demonstrated. There is a need to increase public awareness on the value of early diagnosis of breast cancer. Also, health system should be improved to enable early diagnosis and treatment of this affection.

\section{Keywords}

Breast Cancer, Delay in Consultation, Delay in Diagnosis, Delay in Treatment

\section{Introduction}

Breast cancer is a public health problem because of its frequency and severity. It is the most common female cancer with 2.4 million new cases and 523,000 deaths worldwide reported in 2015 [1]. Its incidence continues to rise in both developed and developing countries [2]. In Cameroon, it is the most common cancer in women with a frequency of $18.5 \%$ of all cancers, and $32 \%$ of female cancers specifically [3].

Breast cancer survival has gradually improved in developed countries over the years. In the United States, the 5-year survival among African American women increased from $71 \%$ to $80 \%$ between 1999 and 2016, and from $87 \%$ to $91 \%$ among Caucasian American women [4]. On the contrary, in developing countries, breast cancer is often in an advanced stage at the time of diagnosis and the survival rate is generally low [5] [6] [7]. In 2016, a hospital series collected in Cameroon at the Yaoundé General Hospital (YGH) estimated the overall 5-year survival rate for breast cancer at $30 \%$ [8].

Breast cancer survival depends on several prognostic factors, one of the most important being the stage of the disease. Delays in consultation, diagnosis and management are among the factors that influence disease stage [9]. Therefore evaluating delays appears to be a potential marker for access to care. Assessing and reducing these is an important goal in the fight against cancer. In Africa, some studies evaluating these delays have been carried out [10] [11] [12] [13] [14]. However, there is a paucity of data on this subject in Cameroon. It is within this framework that we set out to study the delays for consultation, diagnosis and treatment of breast cancer in patients managed at the $\mathrm{YGH}$ in Cameroon.

\section{Material and Methods}

This was a cross-sectional study conducted primarily from hospital registries and medical records of patients followed up for breast cancer at the YGH from January 1, 2014 to April 30, 2018. The YGH is a tertiary referral hospital. This study included 183 breast cancer patients with a confirmed pathology diagnosis. We did not include male patients. In some cases, we made telephone calls to pa- 
tients to complete data missing from medical records.

For each patient, the variables of interest sought included socio-demographic status, clinical and histopathological aspects, consultation delays (time elapsed between the awareness of first signs of disease and the intial consultation), the delay to diagnosis (time lapse between the initial consultation and pathological diagnosis of breast cancer), treatment delays (interval between pathological diagnosis and treatment onset), the health system delay (time elapsed between the initial consultation and management) and the overall delay (time elapsed from awareness of first signs of disease to treatment onset).

Data were entered using SPSS software version 20.0. Shapiro-Wilk statistical tests were used to verify the normalcy of the distribution of quantitative data. Each quantitative variable was attributed a mean, standard deviation, or a median with extremes or interquartile intervals for variables whose distribution was not normal. Qualitative variables were represented by their frequency. The time frames were represented by the median with interquartiles ranging from $25 \%$ $75 \%$. The $\mathrm{Chi}^{2}$ and Fischer exact tests were used to determine the association of qualitative variables with a significance level of $\mathrm{p} \leq 5 \%$. The degree of association was measured by calculating the odds ratio with a $95 \%$ confidence interval. The median delay to consultation was used to dichotomize the study population to determine, by logistical regression, the factors associated with consultation delays above the median. We obtained the authorization of the medical manager of YGH and the consent of the patients.

\section{Results}

Table 1 shows the sociodemographic characteristics of the study population. The patients had a mean age of $48.62 \pm 11.52$ years. The most represented age group was $40-49$ years with a frequency of $37.71 \%$. More than half of patients (59\%) had a high school education. Majority of patients (65.6\%) were married. Three-quarters of the population studied (75.1\%) lived in urban areas. Just under half of the patients were unemployed and just over half had an income below the Interprofessional Growth Minimum Wage (IGMW) in Cameroon, which is 36,270 Fcfa (55 Euros). Treatment was financed primarily by family members ( $68.3 \%$ of cases).

Table 2 shows the clinical and pathological characteristics of the study population. The manner of discovery of the disease was, in most cases $(79.8 \%)$, a positive finding on the breast or axilla. The chief complaint was in almost all cases (90\%) the discovery of a lump in the breast or armpit. A large proportion of our study population (62.8\%) had advanced stage breast cancer (T3 or T4). At their initial consultation, over half of patients (55.4\%) had already met a general practitioner, $35.6 \%$ a specialist, and $9 \%$ a nurse.

A family history of breast cancer was found in $16.9 \%$ of patients. In addition, in half of the cases (51.1\%), breast cancer was diagnosed after consulting at least two health care professionals. The most common histopathological type found was infiltrating ductal carcinoma (84.7\%). The most common therapeutic modality administered was neoadjuvant chemotherapy (71\%). 
Table 1. Sociodemographic characteristics of study population.

\begin{tabular}{|c|c|c|c|}
\hline \multirow{2}{*}{\multicolumn{2}{|c|}{ Variables }} & \multicolumn{2}{|c|}{$\mathrm{N}=183$} \\
\hline & & $\mathrm{n}$ & $\%$ \\
\hline \multirow{6}{*}{ Age (year) } & $20-29$ & 09 & 4.9 \\
\hline & $30-39$ & 27 & 14.8 \\
\hline & $40-49$ & 69 & 37.7 \\
\hline & $50-59$ & 47 & 25.7 \\
\hline & $60-69$ & 22 & 12 \\
\hline & 70 and above & 9 & 4.9 \\
\hline \multirow[b]{2}{*}{ Residence } & Rural & 44 & 24 \\
\hline & Urbain & 139 & 75.9 \\
\hline \multirow{3}{*}{ Marital status } & Single & 24 & 13.1 \\
\hline & Married & 120 & 65.6 \\
\hline & Other & 35 & 19.1 \\
\hline \multirow{4}{*}{ Level of education } & Unschooled & 24 & 13 \\
\hline & Primary & 50 & 27.3 \\
\hline & Secondary & 108 & 59 \\
\hline & High school & 2 & 1 \\
\hline \multirow{4}{*}{ Profession } & Public sector & 45 & 24.6 \\
\hline & Private sector & 13 & 7.1 \\
\hline & Private informal sector & 42 & 23 \\
\hline & Unemployed & 83 & 45.3 \\
\hline \multirow{3}{*}{ Monthly income } & $<\mathrm{IGMW}^{*}$ & 112 & 61.9 \\
\hline & $\geq \mathrm{IGMW}$ & 69 & 38.1 \\
\hline & Spouse & 43 & 23.5 \\
\hline \multirow{4}{*}{$\begin{array}{l}\text { Primary resource } \\
\text { for funding care }\end{array}$} & Family members & 125 & 68.3 \\
\hline & Personal income & 7 & 3.8 \\
\hline & Health insurance & 4 & 2.2 \\
\hline & Other & 4 & 2.2 \\
\hline
\end{tabular}

${ }^{\star}$ Interprofessional growth minimum wage.

Table 2. Clinical and histopathological characteristics of study population.

\begin{tabular}{|c|c|c|c|}
\hline \multicolumn{2}{|c|}{ Variables } & \multicolumn{2}{|c|}{$N=183$} \\
\hline & & $\mathrm{n}$ & $\%$ \\
\hline \multirow{3}{*}{ Discovery mode } & Call signs & 146 & 79.8 \\
\hline & Breast self examination & 36 & 19.2 \\
\hline & Screening mammogram & 01 & 0.6 \\
\hline
\end{tabular}




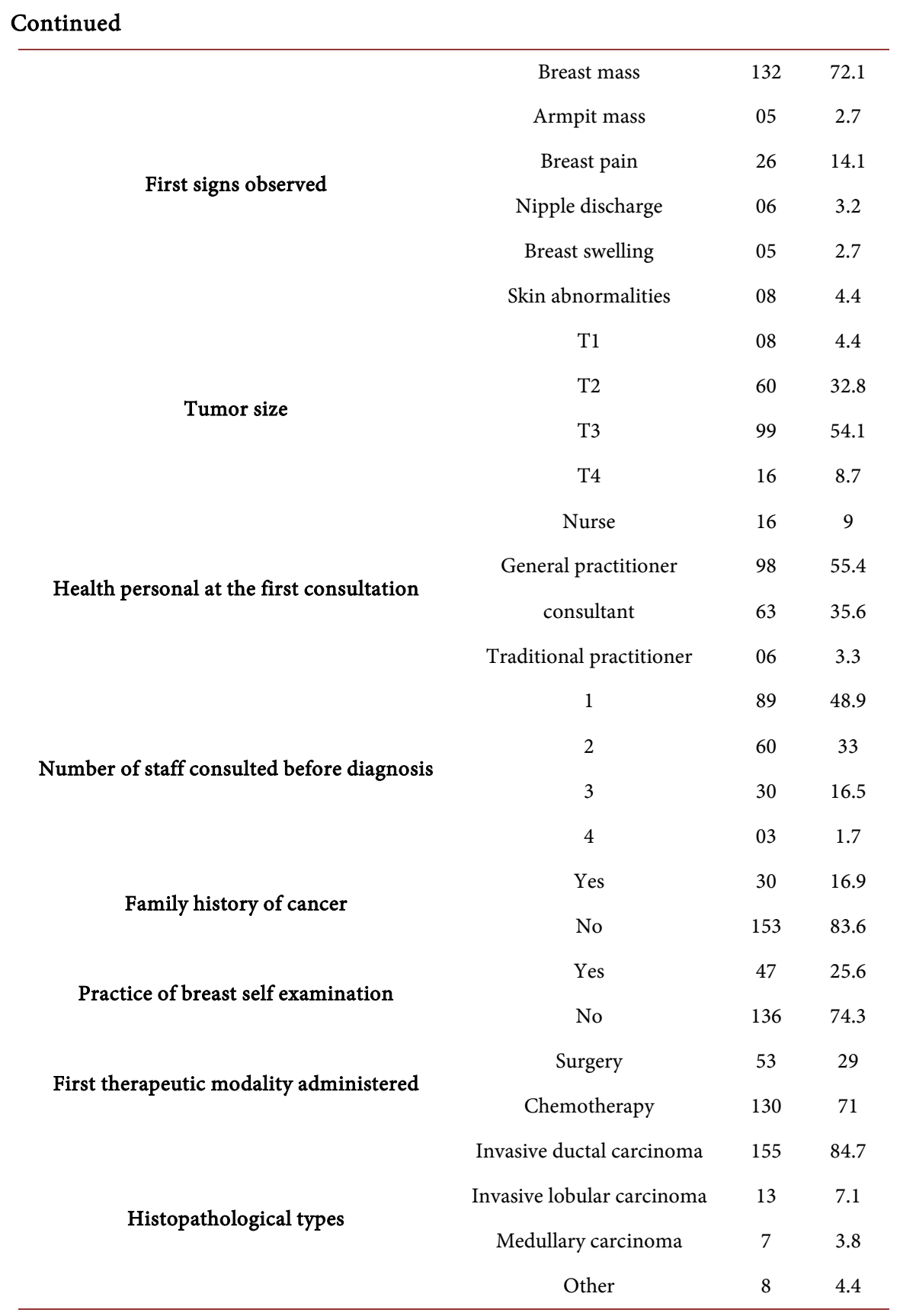

Table 3 shows the medians of the different delays: for consultation 5.1 [1.7 12.4] months; 25 [10 - 67] days and 27 [13 - 63] days for diagnosis and treatment, respectively. The median health system delay was 2.2 [1.2 - 5.8] months and the overall median delay was 9.9 [4.4 - 17.6] months. Whereas, $65.3 \%$ of patients had their first consultation more than 3 months after their initial symptom, $47 \%$ had their initial consultation more than 6 months later.

Table 4 demonstrates, in multivariate analysis, the association between certain socio-demographic and clinical variables and the delay for the first consultation $\geq 5.1$ months. Absence of schooling (OR: 2.01 (1.66 - 2.4)); monthly income less than IGMWC (OR: 2.70 (1.38 - 5.25)), unemployed status (OR: 2.14 
Table 3. Determination of the medians of the different delays.

\begin{tabular}{ccc}
\hline Delay & Median & $\mathrm{II}^{*}(\mathbf{2 5 \%}-\mathbf{7 5 \% )}$ \\
\hline Delay for consultation (months) & 5.1 & $1.7-12.4$ \\
Delay for diagnosis (days) & 25 & $10-67$ \\
Delay for treatment (days) & 27 & $13-63$ \\
Health system delay (months) & 2.2 & $1.2-5.8$ \\
Overall delay (months) & 9.9 & $4.4-17.6$ \\
\hline
\end{tabular}

*Interquartile interval.

Table 4. Determination of the variables associated with a late first consultation at 5.1 months or more.

\begin{tabular}{|c|c|c|c|c|}
\hline \multirow{2}{*}{ Variables } & \multicolumn{4}{|c|}{ Delay for consultation } \\
\hline & $<5.1$ months & $\geq 5.1$ months & Odd Ratio ( $95 \% \mathrm{CI}^{* *}$ ) & $\mathrm{p}$ \\
\hline \multicolumn{5}{|l|}{ Age (years) } \\
\hline$<45$ & 29 & 34 & & \\
\hline $45-65$ & 44 & 45 & $0.87(0.33-1.2)$ & 0.17 \\
\hline$>65$ & 7 & 11 & $1.34(0.471-3.2)$ & 0.57 \\
\hline \multicolumn{5}{|l|}{ Residence } \\
\hline Urban & 66 & 60 & & \\
\hline Rural & 19 & 25 & $1.44(0.61-2.44)$ & 0.59 \\
\hline \multicolumn{5}{|c|}{ Marital status } \\
\hline Married & 50 & 51 & & \\
\hline Single & 30 & 36 & $1.17(0.63-2.19)$ & 0.62 \\
\hline \multicolumn{5}{|c|}{ Health insurance } \\
\hline Yes & 1 & 3 & & \\
\hline No & 86 & 80 & $0.3(0.03-3.04)$ & 0.31 \\
\hline \multicolumn{5}{|l|}{ Tumor size } \\
\hline $\mathrm{T} 1-\mathrm{T} 2$ & 46 & 41 & & \\
\hline $\mathrm{T} 3-\mathrm{T} 4$ & 14 & 69 & $5.53(2.71-11.27)$ & 0.00 \\
\hline \multicolumn{5}{|c|}{ Monthly income } \\
\hline$\geq$ IGMW & 35 & 20 & & \\
\hline$<$ IGMW & 44 & 68 & $2.70(1.38-5.25)$ & 0.03 \\
\hline \multicolumn{5}{|l|}{ Employed } \\
\hline Yes & 52 & 38 & & \\
\hline No & 36 & 57 & $2.14(1.02-3.24)$ & 0.01 \\
\hline \multicolumn{5}{|c|}{ Family history of cancer } \\
\hline Yes & 21 & 09 & & \\
\hline No & 53 & 84 & $3.70(1.33-5.27)$ & 0.03 \\
\hline \multicolumn{5}{|c|}{ Knowledge on $\mathrm{BSE}^{*}$} \\
\hline Yes & 32 & 23 & & \\
\hline No & 49 & 66 & $1.87(0.79-2.90)$ & 0.21 \\
\hline
\end{tabular}

${ }^{\star}$ Breast self examination; ${ }^{\star *}$ Confidence interval. 
(1.02 - 3.24)) and advanced stage of breast cancer (OR: $5.53(2.71$ - 11.27)) were significantly associated with the $\geq 5.1$ months delay in the initial consultation.

Regarding the reasons for a delayed initial consultation beyond 3 months, 108 patients involved in our study mentioned as main reasons: ignorance $(60.2 \%$ of cases), lack of finances (17.6\% of cases) and the use of alternative treatments (11.1\% of cases).

\section{Discussion}

We studied the delays to consultation, diagnosis and treatment of a group of 183 breast cancer patients, who were managed at Yaounde General Hospital in Cameroon. Delays in receiving care are partly responsible for the advanced stage of the disease on presentation [15]. In our study, the median time to consultation also called median patient delay was 5.1 months. In 2015, Pace et al. found a median time to consultation of 5 months in Rwanda similar to our results [14]; in 2009, Clegg et al. reported a median delay of 7.9 months in Ghana [12] and in 2013, Mbucka et al. found a median delay of 9.5 months in Botswana [16].

Meanwhile European authors report median delays to consultation different from ours in four studies: 28 days by Latrache et al., 2004-France [17], 13 days by Nosarti et al., 2000-Great Britain [18], 31 days by Montella et al., 2001-Italy [19] and 16 days by Arndt et al., 2001-Germany [20]. This marked difference reflecting longer delays to consultation in African countries compared to those in Europe could be explained by multiple factors, such as ignorance, poverty and limited access to healthcare in Africa [21].

In our study, the median delay to diagnosis was 25 days. In 2003-Germany, Arndt et al. reported a median delay to diagnosis of 12 days [20] and in 1999-Egypt, Abdel-Fatah et al. reported 7 days [22]. The median delay to diagnosis was longer in our study as a result of limited affordability and long wait times for availability of pathology results confirming breast cancer in our setting.

The median delay to treatment onset was 27 days in our study. Our result is similar to those of studies conducted in 2015 and 2016 in Maghrebi countries (Morocco and Tunisia) by Benbakhta et al. and Manel et al., respectively, who reported a median delay to treatment of 25 days [10] and 35 days, respectively [13]. However, in 2003-Germany, Arndt et al. reported a median delay to treatment of 14 days [20]. These longer delays to treatment in studies conducted in African countries are mainly justified by the absence or inadequacy of the health insurance system in African countries. Patients are obliged to pay out of pocket or by family members for cancer treatment, which is often expensive.

The median health system delay was 2.2 (IIQ: 1.2 - 5.8) months in our study. In 2011 in Colombia Pineros et al. reported a median health system delay of 138 days [23]; in 2016-Tunisia, Manel et al. reported a median delay of 52 days [13], in 2003-Germany, Arndt et al. reported a median delay of 15 days [20], and in 2000-UK, Nosarti et al. reported a median delay of 14 days [18]. This considerable difference in health system delays between developing and developed countries is logically the result of limited access to diagnosis and oncology treatment 
in developing countries due mainly to the delay in the delivery of biopsy results, the absence or discontinuous availability of oncology treatment and the lack of health insurance in a context of poverty of this population.

The maximum acceptable delays for diagnosis or treatment are not clearly defined in the literature. We report that factors associated with a longer delays to consultation, corresponding to a median of $\geq 5.1$ months include: unschooled patients, monthly income below the CIMS level, unemployment status, lack of a family history of cancer, and an advanced stage of the disease (T3 - T4) at the time of diagnosis. Similarly in Morocco, Benbakhta et al. in 2013 found that a low socioeconomic status and lack of a family history of cancer were associated with significantly longer delays to consultation [10]. Also, in 2013-South Africa, Tessa et al. identified the absence of a family history of cancer as a factor associated with a long patient delay [24]. In general, health insurance is absent in developing countries, and the patient must finance her medical care. Thus, a low monthly income would be a factor in delaying access to care for disadvantaged populations. In addition, patients with a family history of cancer would be made aware of the potential severity of cancer, leading them to seek consultation rapidly.

We found no significant association between long patient delays and factors such as age, residential background, marital status, occupation and knowledge of breast self-examination. As in our study, in 2010-Nigeria, Ezeome et al. found no significant association between long consultation delays and factors such as age, marital status and living environment [11].

In our study, the reasons cited by patients to justify the long delays to consultation of more than 3 months were essentially ignorance (60.2\%), lack of financial resources $(17.6 \%)$ and a predilection for alternative treatments (11.1\%). These results corroborate the observations of some authors found in the literature, notably Pace et al. in Rwanda who had identified ignorance (76\%), predilection of alternative treatments (21\%), and poverty (14\%) as the main barriers to rapid consultation [14]. Ezeome et al. in Nigeria had also identified as reasons for delaying consultation: ignorance $(51.1 \%)$, poverty $(13.9 \%)$, the preference for alternative treatments (12.6\%) [11].

The main limitation of this study is that it was carried out in a reference hospital, which is not always accessible to segments of the population with a low socio-economic status. Meanwhile, this health care facility is one of the main centers for cancer management in Cameroon and therefore receives a large proportion of breast cancer patients.

\section{Conclusion}

We found that delays to consult, diagnose and treat breast cancer in our environment are long compared to those reported in developed countries. Factors associated with longer delays prior to consultation include: the unschooled, low patient income, lack of a family history of cancer, and an advanced stage of the disease. There are certainly also institutional factors that are involved. Ignor- 
ance, lack of financial means and the use of alternative treatments are the main reasons for the delay to the initial consultation. Efforts must be directed towards raising public awareness on breast cancer screening and the value of early diagnosis, as well as improving accessibility to diagnosis and management for our population.

\section{Conflicts of Interest}

The authors declare no conflicts of interest regarding the publication of this paper.

\section{References}

[1] Fitzmaurice, C., Allen, C., Barber, RM., et al. (2017) Global, Regional, and National Cancer Incidence, Mortality, Years of Life Lost, Years Lived with Disability and Disability-Adjusted Life-Years for 32 Cancer Groups, 1990 to 2015: A Systematic Analysis for the Global Burden of Disease Study. JAMA Oncology, 3, 524-548. https://doi.org/10.1001/jamaoncol.2016.5688

[2] Ferlay, J., Soerjomataram, I., Dikshit, R., et al. (2015) Cancer Incidence and Mortality Worldwide: Sources, Methods and Major Patterns in GLOBOCAN 2012. International Journal of Cancer, 136, 359-386. https://doi.org/10.1002/ijc.29210

[3] Enow Orock, G.E., Doh, A.S. and Ndom, P. (2012) Current Cancer Incidence and Trends in Yaoundé, Cameroon. Oncology, Gastroenterology and Hepatology Reports, 1, 58-63. https://doi.org/10.5530/ogh.2012.1.14

[4] Siegel, R.L., Miller, K.D. and Jemal, A. (2016) Cancer Statistics, 2016. CA: A Cancer Journal for Clinicians, 66, 7-30. https://doi.org/10.3322/caac.21332

[5] World Health Organization (2012) Rapport sur le Cancer du sein. http://www.who.int/cancer/events/breast_cancer_month/fr/index.html

[6] Mayi-Tsonga, S., Belembaogo, E., Meyé, J.F., et al. (2009) Les Cancers du sein au Gabon: Aspects épidémiologiques, Diagnostique et thérapeutique. African Journal of Cancer, 1, 11-15. https://doi.org/10.1007/s12558-008-0003-y

[7] Kemfang Ngowa, J.D., Yomi, J., Kasia, J.M., et al. (2011) Breast Cancer Profile in a Group of Patients Followed up at the Radiation Therapy Unit of the Yaoundé General hospital, Cameroon. Obstetrics and Gynecology International, 2011, Article ID: 143506. https://doi.org/10.1155/2011/143506

[8] Kemfang Ngowa, J.D., Kasia, J.M., Yomi, J., et al. (2015) Breast Cancer Survival in Cameroon: Analysis of a Cohort of 404 Patients at the Yaoundé General Hospital. Advances in Breast Cancer Research, 4, 44-52. https://doi.org/10.4236/abcr.2015.42005

[9] Williams, M.W. (2008) The Cancer Reform Strategy. Clinical Oncology, 20, 271-274. https://doi.org/10.1016/j.clon.2008.01.014

[10] Benbakhta, B., Tazi, M., Benjaafar, N., et al. (2015) Determinants of Patient Band Health System Delays for Women with Breast Cancer in Maroco 2013. Revue d'Épidémiologie et de Santé Publique, 63, 191-201. https://doi.org/10.1016/j.respe.2015.03.121

[11] Ezeome, E.R. (2010) Delay in Presentation and Treatment of Breast Cancer in Enugu Nigeria. Nigerian Journal of Clinical Practice, 13, 311-316.

[12] Clegg-Lamptey, J., Dakubo, J. and Attobra, Y.N. (2009) Why Do Breast Cancer Patients Report Late or Abscond During Treatment in Ghana? A Pilot Study. Ghana 
Medical Journal, 43, 127-131. https://doi.org/10.4314/gmj.v43i3.55338

[13] Manel, L., Thouraya, A., Chekib, Z., et al. (2016) Étude des délais de Traitement du cancer du sein à Sousse, Tunisie. Santé Publique, 28, 331-340.

https://doi.org/10.3917/spub.163.0331

[14] Pace, L.E., Mpunga, T., Hategekimana, V., et al. (2015) Delays in Breast Cancer Presentation and Diagnosis at Two Rural Cancer Referral Centers in Rwanda. Oncologist, 20, 780-788. https://doi.org/10.1634/theoncologist.2014-0493

[15] Tartter, P.I., Pace, D., Frost, M. and Bernstein, J.L. (1999) Delay in Diagnosis of Breast Cancer. Annals of Surgery, 229, 91-96.

https://doi.org/10.1097/00000658-199901000-00012

[16] Mbuka-Ongona, D. and Tumbo, J.M. (2013) Knowledge about Breast Cancer and Reasons for Late Presentation by Cancer Patients Seen at Princess Marina Hospital, Gaborone, Botswana. African Journal of Primary Health Care \& Family Medicine, 5, 465. https://doi.org/10.4102/phcfm.v5i1.465

[17] Latrache, C., Desandes, E., Mayeux, D., et al. (2004) Délai de Prise en Charge des Patientes Atteintes d'un Cancer du sein dans un réseau régional de soins en cancérologie: faisabilité d'un Programme Personnalisé de soins. Bulletin du Cancer, 91, 965-971.

[18] Nosarti, C., Crayford, T. and Roberts, J.V. (2000) Delay in Presentation of Symptomatic Referral to a Breast Cancer Clinic Patient and System Factors. British Journal of Cancer, 82, 742-748. https://doi.org/10.1054/bjoc.1999.0990

[19] Montella, M., Crispo, A., D’Aiuto, G., et al. (2001) Determinant Factors for Diagnostic Delay in Operable Breast Cancer Patients. European Journal of Cancer Prevention, 10, 53-59. https://doi.org/10.1097/00008469-200102000-00006

[20] Arndt, V., Stürmer, T., Stegmaier, C., et al. (2002) Patient Delay and Stage of Diagnosis among Breast Cancer Patients in Germany-A Population-Based Study. British Journal of Cancer, 86, 1034-1040. https://doi.org/10.1038/sj.bjc.6600209

[21] Ly, M., Antoine, M., André, F., et al. (2011) Le Cancer du sein chez la Femme de l'Afrique Sub-Saharienne: Etat Actuel des Connaissances. Bulletin du Cancer, 98, 797-806. https://doi.org/10.1684/bdc.2011.1392

[22] Abdel-Fattah, M.M., Anwar, M.A., Mari, E., et al. (1999) Patient and System Related Diagnosis Delay in Breast Cancer. European Journal of Public Health, 9, 19-15. https://doi.org/10.1093/eurpub/9.1.15

[23] Piñeros, M., Sánchez, R., Perry, F., Armando, G.O., Ocampo, R. and Cendales, R. (2011) Delay for Diagnosis and Treatment of Breast Cancer in Bogota, Colombia. Salud Pública de México, 53, 478-485.

[24] Tessa, M.S., Lunda, S. and Fernandez, L. (2013) Delay Breast Cancer Presentation: Hospital Data Should Inform Proactive Primary Care. African Journal of Primary Health Care \& Family Medicine, 5, 503. https://doi.org/10.4102/phcfm.v5i1.503 